\title{
Integrating the History of Mathematics into Mathematics Education: A Case Study of Teaching the Quadratic Equations
}

\author{
Duong Huu Tong ${ }^{1, *}$, Nguyen Phu Loc ${ }^{1}$, Bui Phuong Uyen ${ }^{1}$,Tran Thi $Y^{2}$ \\ ${ }^{1}$ School of Education, Can Tho University, Vietnam \\ ${ }^{2}$ An Thoi High School, Can Tho City, Vietnam
}

Received September 25, 2019; Revised October 21, 2019; Accepted October 28, 2019

Copyright@2019 by authors, all rights reserved. Authors agree that this article remains permanently open access under the terms of the Creative Commons Attribution License 4.0 International License

\begin{abstract}
Mathematics is an important subject in high schools, but it is quite a difficult and arid subject. Therefore, in order to create interest in learning and explore knowledge for students, teachers need to choose appropriate teaching methods. There are many different teaching methods including integrated ones. Currently, integrating the history of mathematics into teaching is of interest to many researchers. With the topic of integrating mathematical history, the goal that the research set out was to introduce the methods of infusing mathematical history into teaching quadratic equations through worksheets. This study was conducted with 44 10th grade students at a high school in Soc Trang province, Vietnam. The content of the worksheets introduced students to four methods of solving quadratic equations, two of which belonged to two famous mathematicians, Viète and Descartes. After reading and comprehending the solution methods, students would solve the equations according to the four given methods. At the end of the lesson, the researchers collected the students' opinions through the questionnaire. Through analysis of survey results, it was shown that teaching integrated the mathematical history with worksheets created excitement and interest for students, thus making them more motivated and creating a comfortable classroom atmosphere.
\end{abstract}

Keywords Integrating, History of Mathematics, Quadratic Equation, Solution Method, Mathematics Education

\section{Introduction}

Every science has its history of formation and development, of which mathematics is no exception. Mathematical history records valuable mathematical achievements associated with its founders, the great mathematicians. Therefore, teaching mathematics also needs to show learners the history of the internal mathematics itself, and mathematical problems in history can be taught in high schools, even the difficulties that mathematicians encounter also cause obstacles for students to comprehend them. When studying the integration of mathematical history in the classroom, some issues also need to be clarified as follows: the benefits, the difficulties that teachers may encounter, and the ways to incorporate it into teaching.

Incorporating the history of mathematics into teaching is regarded as an effective tool to promote students' learning because it has many situations that can be used as examples, and infusing them into teaching attracts the attention and curiosity of students $[1,8,15,17]$. Also, this way of teaching appears to improve the awareness of students and teachers, and at the same time, common anxiety of students about mathematics is also reduced. In addition, it can aid teachers and students in explaining many questions why can arise in class $[6,10,11]$.

Through studying mathematical history and using it into teaching mathematics, teachers will be more aware, able to understand and better solve the obstacles students encounter in learning some concepts and rules [16]. Maybe, students at different levels find obstacles in learning similar to those experienced by mathematicians [15]. From this, students' confidence is increased when they realize that the great mathematicians did not immediately write their answers when they discovered mathematical achievements [17]. Furthermore, history of mathematical development allows both teachers and students to know more about the development characteristics of this science. In fact, it can be useful for students to see how mathematical ideas have been created in the past $[3,20]$. Besides, students see some of the techniques they use today to solve problems that 
have been going on for quite some time $[7,15]$.

Teaching in classrooms is characterized by an integrated perspective of mathematical history that allows students to recognize the culture, politics, social and economic contexts of mathematical development, as well as the important role dominated by many different cultures in the development of mathematics [4]. It is clearly found that mathematical history provides students with many opportunities to study ancient cultures and societies. Indeed, integrating mathematical history into teaching is a great method which can support both teachers and students in recognizing the connection between different fields of mathematics and between mathematics and other subjects $[7,15,20]$.

Although there are many benefits of incorporating mathematical history into classes, it is not an easy task. It is concluded that the personality, enthusiasm, voluntariness and professionalism of teachers decide how to integrate mathematical history into teaching because of their important role in class activities. Sometimes, teachers don't pay much attention to this issue because it is not involved in the assessment of students' mathematical results [9]. Also, lessons with integrated math history are not the main requirements for teachers today.

The lack of teachers' knowledge in mathematical history and about the value and its educational potential is a difficulty in teaching with mathematical history. In the teacher training program, there are not many courses in mathematical history that can cover all the development of mathematics over thousands of years, involving thousands of people and lots of math facts [8, 15, 19]. For example, in most mathematics teacher training programs in Vietnam, there is only one course in mathematical history, even it is an elective module.

Furthermore, another difficult task of teachers is to carefully select relevant mathematical history examples, so that teachers can progress both in mathematical history knowledge and in the ways of infusing them into teaching mathematics. Both teachers and students lack appropriate materials to support the infusion of mathematical history into mathematics classes. Even, teachers do not know much about the methods of incorporating mathematical history into the classrooms $[8,19]$.

In addition to the roles and difficulties of using mathematical history in the classrooms, the teachers should know the effective ways of integrating it. Teachers can find really useful problems, history problems or problems inspired by history that allow both teachers and students to understand the motivation behind the birth and development of many mathematical concepts and processes [4]. There are many ways to use mathematical history in the classroom, including biography, year of birth, visual display of images (time, portrait, stamps, etc.), plays, games, group projects and articles (topics can range from mathematics to aspects of everyday life such as pottery, paintings, etc.). Also, it is helpful to students to discover local history, historical exercises, historical issues of the week, museum visits, outdoor exploration with tools and equipment, videos, movies, slides, Internet surfing and even shows entertainment $[10,16]$.

Teachers should use activities to call for cooperation and investigation from students because they will permit students to do mathematics in different ways to help students realize the value of methods and the power of modern mathematics. Besides, teachers should encourage students to experience as well as explore historical documents and the development of mathematical methods, tools and ideas. Using the biographies of mathematicians can be a good starting point for using mathematical history in the classroom [15]. If using their biographies, it is limited to a few minutes to create curiosity about history, not to learn and explore mathematics, then some questions arise. Indeed, teachers should ask themselves whether the anecdotes about the life or work of a mathematician really motivate students to learn or better understand mathematics or not. Moreover, drama is a form of incorporating mathematical history into teaching, in particular, drama can be designed to recreate the lives of mathematicians in the past, as a way to appreciate the people of mathematical activity [16].

The authors, S. Goktepe \& A. K. Ozdemir [7] asked 20 eighth grade students to find the square root of numbers according to two methods in history and the students had to compare the results calculated by a calculator. The researchers noted that the students were very interested in that activity and had a good chance to compare the methods of calculating square root and evaluated which one was the best.

A Turkish researcher, Butuner [2] organized 24 students to discover the formula for calculating the volume of frustum pyramids using a combination of pieces of wood, a dissection method derived from mathematical history, then the students were asked to answer 4 questions to give feedback about the activity. It was seen that many students had difficulties in formation of shapes and calculation. However, the interview findings revealed that the students were very interested in participating in an instructional activity. To see the effect of infusing mathematical history into algebra classes, the researchers C. Bellomo \& C. Wertheimer [1] organized teaching in an experimental class with mathematical history elements and control class without integrated mathematical history. It was obvious that the test score of history class was higher than the control class. Moreover, student responses to the questionnaire also showed the relationship between learning with mathematical history and improving their understanding was grounded. Also, research results were found that integrating history was also an effective teaching method for two reasons: student's interest in historical topics as well as their relationships and the perception of teachers on this teaching strategy.

Although there were many researches on the effectiveness of historical incorporation for teachers, two Serbian authors also wanted to survey teachers' beliefs and 
attitudes on this issue. The teachers were asked to answer 9 questions designed by M. Dejić \& A. M. Mihajlović [3]. It was clear that most teachers had a positive attitude, but they didn't usually integrate mathematical history in their mathematics classes. The main reasons for this were the lack of teaching materials, methods and limited time in the classroom due to the compulsory curriculum. Meanwhile, some teachers were reluctant to infuse the history of mathematics into teaching because they were not sure of its effectiveness, they even thought that it would make students bored and did not like the way of teaching.

S. Sen [18] said that the history of mathematics played an active role in cognitive development and emotional field of the learners. Therefore, in his work, the ways of discussing historical elements of variable in elementary algebra in classrooms were necessary and these ways were able to support students in having an interest and positive attitude. Using mathematical history to teach a specific topic was of interest to many educators, including the authors J. M. Mendoza and et al. [12] because they had a lesson study of teaching Cartesian coordinate planes. Their research results stressed the value of the use of mathematical history in teaching this topic in areas such as: motivation in teaching, real-life application and purpose and an appreciation of mathematics.

To know more about the perception of teachers involved in using mathematical history in the classroom, the two researchers R. M. Panasuk \& L. B. Horton [13] had a large-scale survey of American teachers and they were asked to answer on-line questions. Many teachers who integrated mathematical history gave a variety of reasons, while teachers who did not integrate mathematical history in the classroom also offered many views for this. For example, they did not know how to infuse mathematical history in the classroom, nor did they have tests related to mathematical history. Besides, the teacher's knowledge of mathematical history was still limited, so it was required to have at least one course in mathematical history in the teacher training curriculum.

Incorporating mathematical history was used not only in high schools but also in college classes. Indeed, $\mathrm{N}$. Haverhals \& M. Roscoe [8] used mathematical history as an educational activity to enrich undergraduate students' understanding through teaching the integral of the secant via Mercator's projection. Although calculating integrals was not easy for many students, they better understood when they were embedded within the scope of mathematical history. The two authors, J. M. Furner \& E. A. Brewer [5] had a study of the connection between mathematics and its history, and they also showed how to connect mathematics that the teachers taught and its past. The researchers also emphasized the benefits of infusing the mathematical history in classes for students such as: more knowledgeable, appreciative and tolerant. From here, the students gained a better understanding and appreciation of where to start the mathematical ideas and contents.

\section{The History of Mathematics in Curriculum and Mathematics Textbooks in Vietnam}

In the general education curriculum for mathematics, it is mentioned that "acquiring mathematical knowledge is only effective when evoking aesthetic feelings in students. Therefore, mathematics contributes to the development of aesthetic competence through familiarizing students with the history of mathematics, with biographies of mathematicians and through recognizing the beauty of mathematics in the natural world". In addition to the content requirements required for knowledge, the mathematics program at each level also gives an appropriate amount of time to carry out practical activities and mathematical experiences for students such as: conducting topics, mathematical learning projects, especially projects and practical mathematical applications; organizing mathematical games, mathematical clubs, forums, seminars, and mathematical contests; publishing a newspaper (or magazine) on mathematics; visiting mathematical training and research institutions, interacting with students who are able and love mathematics. These activities along with mathematical history will equip students with basic general education, assisting students in applying their knowledge, skills and experience in a creative way. As a result, the students see the role of mathematics in practice, thereby making an important contribution to the learning of mathematical knowledge in the classrooms.

In the high school mathematics curriculum, the mathematical textbooks give a brief introduction to mathematicians and some knowledge of mathematical history related to the lesson contents. However, elements of mathematical history are not presented in a complete and thorough manner for all contents of mathematics. Moreover, the current situations of teaching mathematics in high schools now show that teachers pay little attention to this problem because of the limited time of a lesson and insufficient teachers' knowledge of mathematical history. Currently, the source of information on mathematical history is restricted, so the teachers do not have the opportunity to approach and study or delve into the field although it is very important. Therefore, it is necessary for them to learn about mathematical history. Moreover, integrating how to increase students' interest in acquiring knowledge of mathematical history is also a very interesting and important issue for teachers.

In the curriculum, there are many contents that can incorporate mathematical history, such as sets, functions, integrals, derivatives, statistical probability,...teachers can use the mathematical modelling process in teaching, in which they go from a mathematical problem associated with the history of mathematics to create an environment for students to learn and explore mathematical knowledge.

Although integrating mathematical history in the 
classroom is done by many educators in the world, this research is conducted in the context of Vietnam and through teaching a specific topic (quadratic equation). The purpose of the study is to initially evaluate the feasibility and effectiveness of incorporating mathematical history into teaching. More specifically, it is necessary to find the answer to the following question: Does integrating mathematical history into teaching create excitement for students in the learning process, as well as make the classroom atmosphere more lively or is not?

\section{Materials and Methods}

\subsection{Participants}

Experimental objects were 44 students at Thieu Van Choi high school, Ke Sach district, Soc Trang province, Vietnam, a rural school, with difficult conditions for students to study and exploit information. These students had extracurricular activities to learn about four methods of solving quadratic equations through worksheets.

\subsection{The Process of Research}

The research process took place in 4 stages:

- $\quad$ Stage 1: Creating worksheets with four methods to solve quadratic equations.

- $\quad$ Stage 2: Using the worksheets to teach.

- $\quad$ Stage 3: Analyzing the teaching period.

- $\quad$ Stage 4: Surveying to get students' ideas

Creating worksheets helped students solve quadratic equations using different methods, including the method of calculating the discriminant $\Delta$ and using a calculator to compare results. The content of the worksheet involved solving quadratic equations by four methods, including two methods in the history mentioned, in which a algebraic method was proposed by Viète and a geometric method was discovered by Descartes. To create the attention and curiosity of students, the researcher posed the questions:

How do Viète and Descartes solve the quadratic equation correctly? Are the solutions of Viète and Descartes the same? Which solution is better?

The method of solving quadratic equations of Viète:

$$
a x^{2}+b x+c=0(a \neq 0)
$$

Step 1: Put $x=y+z$ and, we obtain:

$$
\begin{gathered}
a(y+z)^{2}+b(y+z)+c=0 \\
\Leftrightarrow a y^{2}+(2 a z+b) y+a z^{2}+b z+c=0
\end{gathered}
$$

Step 2: Give $2 a z+b=0 \Leftrightarrow z=-b / 2 a$

Substitute in the equation, we have:

$a y^{2}+a(-b / 2 a)^{2}+b(-b / 2 a)+c=0 \Leftrightarrow 4 a^{2} y^{2}=b^{2}-4 a c$
From this, we obtain: $y= \pm\left(\sqrt{\left(b^{2}-4 a c / 4 a^{2}\right.}\right)$

Lastly, using the variable $x: x=\left(-b \pm \sqrt{b^{2}-4 a c}\right) / 2 a$

The method of solving quadratic equations of Descartes:

$$
x^{2}-a x-b^{2}=0(a, b>0)
$$

Step 1: Draw a right-angled triangle $A O B$,

$$
O A=(1 / 2) a ; O B=b ; \angle A O B=90^{\circ}
$$

Step 2: Draw a circle with center $A$ and radius $O A$.

Step 3: Prolong $\mathrm{AB}$; the prolongation intersects the circle in $\mathrm{C}$.

Step 4: $x=B C$ is the required line segment.

This is the solution to the quadratic equation.

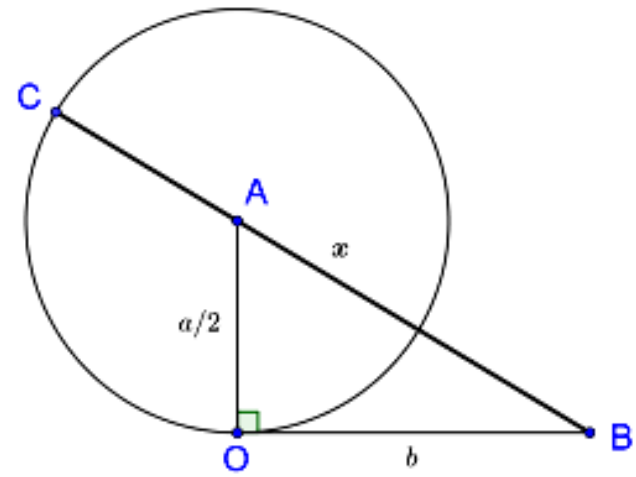

Figure 1. Illustration of Descartes' solution method

The researchers then noticed, with this solution, 'Descartes' method was only built in positive cases $(\mathrm{a}, \mathrm{b}>0)$. In fact, if he used negative numbers in calculations, he didn't give a geometric meaning of negative numbers, therefore, he didn't use negative coordinates".

Then, researchers solved the equation $x^{2}-12 x-64=0$ by using two methods.

Thank to the example, students better understood the methods and the researchers' attention. Clearly, Descartes's method was somewhat more restrictive than Viète's.

Next, the researchers repeated two solution methods that students often use in solving quadratic equations. These are the methods of calculating the discriminant $\Delta$ and using the calculator. The two methods are as follows:

The method to solve quadratic equations by using the quadratic formula is summarized in table 1 :

Table 1. Method of solving quadratic equations by using the quadratic formula

\begin{tabular}{|c|c|}
\hline \multicolumn{2}{|c|}{$a x^{2}+b x+c=0(\mathrm{a} \neq 0)$} \\
\hline$\Delta=b^{2}-4 a c$ & Conclusions \\
\hline$\Delta>0$ & The equation has two distinct roots \\
& $x=(-b \pm \sqrt{\Delta}) / 2 a$ \\
\hline$\Delta=0$ & The equation has double roots $x=-b / 2 a$ \\
\hline$\Delta<0$ & The equation has no real roots \\
\hline
\end{tabular}


The method of using a calculator: For CASIO calculator fx-570ES:

Press the following buttons continuously:

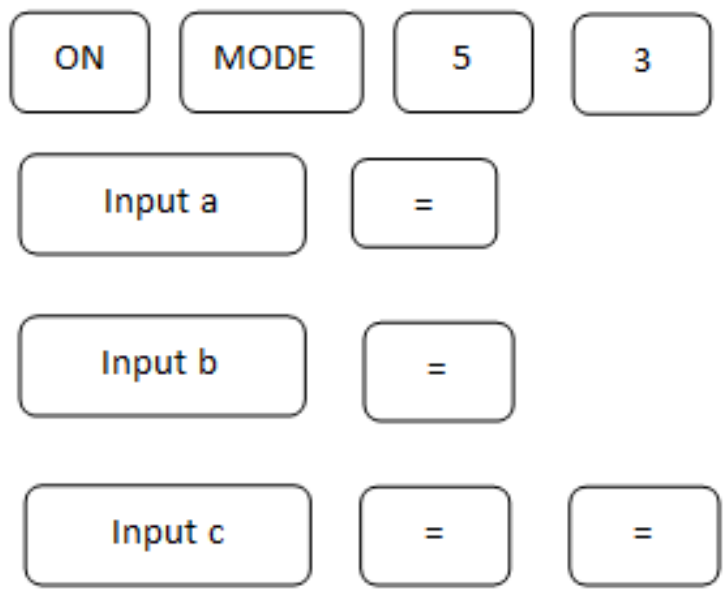

\subsection{Designing the Lesson Process}

The worksheet included four methods for solving quadratic equations that were given to each student. Activities were carried out during a lesson. Here was the teaching process:

1. Stabilizing class organization: Check class size.

2. Teaching the new lesson.

The teacher led into the lesson after dividing the class into 11 groups of 4 students.

Activity 1: Reading the methods for solving quadratic equations.

Teacher: Hand out the worksheet, ask students to carefully read "Activity 1: Viète's method" in the worksheet.

Student: Read the worksheet and discussion.

Teacher: Answer students' questions in activity 1.

Teacher: Ask students to carefully read "Activity 2: Descartes's method" in the worksheet.

Student: Read the worksheet and discussion.

Teacher: Answer students' questions in activity 2.

Teacher: Ask students to read "Activity 3 and 4: The method of calculating the discriminant $\Delta$, using the calculator" in the worksheet.

Student: Read the worksheet and discussion.

Activity 2: Applying the methods to solve a specific equation.

Teacher: Ask students to work in groups in order to discuss how to solve the equation in 4 methods.

Teacher: Call students to come to the board.

Student: Volunteer to come to the board to solve the problem.

Teacher: Call students to comment.

Student: Comment.

Teacher: Comment.

3. Consolidating.

\subsection{Getting Students' Ideas about the Lesson (within 9 Questions)}

Student feedback on integrating mathematical history into lessons was collected through an after-school survey. The questionnaire was distributed to each student and they recorded their opinion on the questionnaire. The questions had the following contents:

Question 1. In your opinion, is the knowledge of mathematical history important to mathematical learners?

Question 2. Do you often study with worksheets that integrate mathematical history?

Question 3. Which of the 4 methods mentioned in the worksheet is meaningful to you? Why?

Question 4. Do you often find out more about the history of mathematics in textbooks?

Question 5. Do the activities that you have done help you become more enthusiastic in acquiring mathematical knowledge?

Question 6. Do you like to participate in the learning activities of teachers integrated with the history of mathematics?

Question 7. What difficulties did you encounter during your activities?

Question 8. What have you learned through recent activities?

Question 9. Do you want to continue studying with similar activities?

In order to analyze students' opinions about teaching mathematics with infusing mathematical history, the researchers used descriptive statistical methods, in particular, we conducted data collection, summary, and presentation, then it was essential to calculate and describe the basic characteristics of the data collected. In this study, the researchers applied both qualitative and quantitative analysis methods. Specifically, answer results were quantitatively analyzed, giving frequency and percentage in questions 1, 2, 4, 5, 6, 7 and 9. The rest cited the specific answer of students and synthesized by qualitative analysis methods.

\section{Results and Discussion}

The researchers recorded some results after the group discussion as follows: Almost all groups followed the method given by the teacher and the results were successful, the success rate of the group was $90.91 \%$. However, there were still groups that made some mistakes in their presentation (for example, the group 2's work on Viète's method):

$$
\begin{gathered}
\text { Let } x=y+z \\
=(y+z)^{2}-6(y+z)-16=0 \\
=y^{2}+2 z y+z^{2}-6 y-6 z-16=0 \\
=y^{2}-(-2 z+16) y+z^{2}-6 z-16=0
\end{gathered}
$$


Or in Descartes' method, the group 2 incorrectly determined the length of the $O B$ segment and the radius of the circle, namely:

Draw a right triangle $A O B$ with $O A=3, O B=6$ and $\angle A O B=90^{\circ}$.

Draw a circle with center A and a radius of 1.5.

In the group 5 , they approached too closely to the method but did not really understood it. This was seen in the step 4, Viète's method:

From (2) and (3), we have: $x=y+z$

$$
=\left(-(-6) \pm \sqrt{(-6)^{2}-4.1(-16)}\right) / 2.1=-2 \text { and } 8
$$

Besides, there were groups that understood and flexibly applied the method, specifically as follows:

Let $x=y+z$, we have: $(y+z)^{2}-6(y+z)-16=0$

$$
\begin{aligned}
& \Leftrightarrow y^{2}+2 z y+z^{2}-6 y-6 z-16=0 \\
& \Leftrightarrow y^{2}+2 y(z-3)+z^{2}-6 z-16=0
\end{aligned}
$$

Instead of using the second equivalent sign method to just set the $y$-factor out, the group flexibly set $2 y$. So to step 2 , the group just needed to set $z-3=0$. Due to their familiarity and proficiency, in the method of using the discriminant $\Delta$ and the calculator, the groups completed easily.

Table 2. Students' opinions about the importance of the mathematical history to mathematical learners

\begin{tabular}{|c|c|c|}
\hline $\begin{array}{c}\text { In your opinion, is the knowledge of } \\
\text { mathematical history important to } \\
\text { mathematical learners? }\end{array}$ & $\mathrm{f}$ & $\%$ \\
\hline Very important & 14 & 31.82 \\
\hline Important & 30 & 68.18 \\
\hline Normal & 0 & 0 \\
\hline Unimportant & 0 & 0 \\
\hline Very unimportant & 0 & 0 \\
\hline
\end{tabular}

$31.82 \%$ of students said that mathematical history was very important to learners, the rest thought it was important. Some reasons given by students were as follows: "Knowing mathematical history, we can better understand the knowledge learned, then apply and create new solutions for some problems", "That is the basis to learn new knowledge and also make an important contribution to teaching and learning mathematics", "Knowing the history of the development of mathematic", "All our living activities are related to mathematics, it is the foundation and when knowing about mathematical history will make us more sensitive",... The answers given by students as above demonstrate the potential value of a teaching method that is integrated with the history of mathematics.

Most students said they rarely (with a percentage of 50\%) or only occasionally (with a percentage of 38.63\%) studied with worksheet with integrated mathematical history. This showed that integrating mathematical history with worksheets had not been paid much attention. This can also be explained by the fact that the sections on mathematical history are only considered as an additional reading in the textbooks, so teachers do not see them as a main teaching activity.

Table 3. Students' opinions about how often they are learning with a worksheet that incorporates mathematical history

\begin{tabular}{|c|c|c|}
\hline $\begin{array}{c}\text { Do you often study with worksheets that integrate } \\
\text { mathematical history? }\end{array}$ & $\mathrm{f}$ & $\%$ \\
\hline Very often & 0 & 0 \\
\hline Often & 3 & 6.83 \\
\hline Occasionally & 17 & 38.63 \\
\hline Rarely & 22 & 50 \\
\hline Never & 2 & 4.55 \\
\hline
\end{tabular}

Table 4. Students' ideas in the 4 solving methods mentioned in the worksheet which way makes sense to them

\begin{tabular}{|c|c|}
\hline $\begin{array}{c}\text { Which of the } 4 \text { methods mentioned in the worksheet is } \\
\text { meaningful to you? Why? }\end{array}$ & $\%$ \\
\hline Viète's method & 38.64 \\
\hline Descartes' method & 6.83 \\
\hline The method of calculating the discriminant $\Delta$ & 56.82 \\
\hline Method of using a calculator & 75 \\
\hline
\end{tabular}

Most of the students were inclined to use the calculator $(75 \%)$ and the discriminatory method $\Delta(56.82 \%)$. Besides, although Viète's solution method was a new approach, it also accounted for a high proportion (38.64\%). The students explained their options as follows: for Viète's method: "Knowing the origin to get an empirical formula and gaining a deeper understanding of how to solve quadratic equations", "Finding sufficient and easy solutions to understand" , "This method explains in detail and achieves accurate results"; for Descartes' method: "Being able to apply geometry to solve equations makes me feel new but it still has shortcomings", "Can be applied quickly", "Help me learn new methods of solving mathematical problems"; for the discriminant method $\Delta$ "Easy to understand, easy to do, quick and easy to make mistakes", "Simple, does not take much time"; For the method of using a calculator "Very fast, with high accuracy", "Compact, easy to carry, saving time", "Pocket calculator is a learning tool to help me quickly solve the problem of equation, however, it is only suitable for taking quizzes and not for essay-solving ". In general, the following two solution methods were preferred by students because they were very familiar to students from junior high to 10th grade.

$61.37 \%$ of students said that they only occasionally read the additional readings, the number of students who regularly or rarely learned together accounted for the frequency of $18.18 \%$, the number of students who were often learning was only $2.27 \%$. In general, the majority of students also did not regularly read the history of mathematics in textbooks, for the reason that it may not participate in the assessment of academic results or is not 
included in the test. Because there were still some students who were not interested in further reading about the history of mathematics in textbooks, teachers can encourage them about this to show them how the mathematical achievements were happening in history.

Table 5. Students' opinions about how often they read additional sections about mathematical history in textbooks

\begin{tabular}{|c|c|c|}
\hline $\begin{array}{c}\text { Do you often find out more about the history of } \\
\text { mathematics in textbooks? }\end{array}$ & $\mathrm{f}$ & $\%$ \\
\hline Very often & 1 & 2.27 \\
\hline Often & 8 & 18.18 \\
\hline Occasionally & 27 & 61.37 \\
\hline Rarely & 8 & 18.18 \\
\hline Never & 0 & 0 \\
\hline
\end{tabular}

Table 6. Students' opinions about the activities helping them more enthusiastically to acquire mathematical knowledge

\begin{tabular}{|c|c|c|}
\hline $\begin{array}{c}\text { Do the activities that you have done help you } \\
\text { become more enthusiastic in acquiring } \\
\text { mathematical knowledge? }\end{array}$ & $\mathrm{f}$ & $\%$ \\
\hline Very excited & 10 & 22.73 \\
\hline Excited & 34 & 77.27 \\
\hline Normal & 0 & 0 \\
\hline Not excited & 0 & 0 \\
\hline Very unexcited & 0 & 0 \\
\hline
\end{tabular}

Most students were excited or very excited about the activities because of some explanations of students such as: "Bring knowledge, fun learning", "Help me be more active", "Comfortable learning space, easier to acquire knowledge", "Easy to absorb the lesson, doing activities with friends, learning in a group is very fun", "This is a meaningful activity, stimulating thought, helping to increase creativity and acquire our own knowledge", "While having fun more easily receptive, remember all the time",... The excitement of students in the activities involved had brought more information about the effectiveness of this teaching method because they had been active in cognitive activities.

Table 7. Students' opinions about whether they like to participate in the learning activities of teachers integrated with the history of mathematics

\begin{tabular}{|c|c|c|}
\hline $\begin{array}{c}\text { Do you like to participate in the learning activities } \\
\text { of teachers integrated with the history of } \\
\text { mathematics? }\end{array}$ & $\mathrm{f}$ & $\%$ \\
\hline Very like & 14 & 31.82 \\
\hline Like & 29 & 65.91 \\
\hline Normal & 1 & 2.27 \\
\hline Dislike & 0 & 0 \\
\hline Very dislike & 0 & 0 \\
\hline
\end{tabular}

The statistics showed that most students liked to participate in activities to learn about mathematical history. Here were some typical answers: "Want to learn more about the old way and compare it with the current way", "It suits me", "Comfortable in learning mathematics, can understand lessons quickly"," Fun, excited "... One implication was found that through learning with four methods of solving, they were very excited and had active faith in similar lessons. This initial effect can be further developed with the ways of integrating the mathematical history outlined in the literature.

Table 8. The difficulties students faced in carrying out the activities

\begin{tabular}{|c|c|}
\hline $\begin{array}{c}\text { What difficulties did you encounter during your } \\
\text { activities? }\end{array}$ & $\%$ \\
\hline Understanding the method & 25 \\
\hline Calculating & 9.09 \\
\hline Drawing & 20.45 \\
\hline Applying methods to solve the exercises & 15.91 \\
\hline No difficulty & 54.55 \\
\hline
\end{tabular}

In $54.55 \%$ of the students almost had no difficulty. However, there was a case where the opinion, "There is a method of a scientist, I do not understand why I know the edge $O A=1 / 2 a, O B=b^{\prime \prime}$. This proved that when teaching integrated mathematical history, it stimulated students' curiosity about mathematics and students had mathematical questions and thoughts. Furthermore, there were some ideas presented as follows: "During the process of solving homework, I had difficulty when the method was too complicated, did not go straight to the problem, so I could not apply", "Need a lot of time to solve, a little confusing and a little headache", "Easy to wrong, so it often leads to wrong results", "I need more time for this",... It was clear that the two methods from the history of mathematics that had brought certain difficulties for students. For instance, the method of Viète made it difficult for students to interact with algebraic transformations. Meanwhile, the method of Descartes had the complexity of the image and understanding its geometric meaning.

Table 9. What students learned through activities

\begin{tabular}{|c|c|}
\hline What have you learned through recent activities? & $\%$ \\
\hline Reinforce knowledge of solving quadratic equations & 84.09 \\
\hline Know more solutions of quadratic equations & 97.73 \\
\hline Get more knowledge about mathematical history & 41 \\
\hline How to use a calculator & 70.45 \\
\hline Learn the unknown & 86.36 \\
\hline Train your ability to solve problems & 86.36 \\
\hline Brain training & 81.82 \\
\hline
\end{tabular}

After participating in the activities, the students said that they could learn more about other solutions of quadratic equations (with the rate of $97.73 \%$ ). Because it was the first time the students had access to new solutions, self-study methods on the learning card should train students to solve problem problems (86.36\%). Besides, it also supported students in learning unknown things (accounting for $86.36 \%$ ), maybe the method of using a calculator was familiar to them so the rate was not high, $41 \%$. This can be 
deduced that students learn a lot through the tasks already done. Generally, that implies that mathematical activities integrated with mathematical history are effective in many areas such as: broaded knowledge, positive attitudes and optimistic beliefs in mathematical achievements in history.

Table 10. Students' opinions about whether they want to continue learning with similar activities

\begin{tabular}{|c|c|c|}
\hline $\begin{array}{c}\text { Do you want to continue studying with similar } \\
\text { activities? }\end{array}$ & $\mathrm{f}$ & $\%$ \\
\hline Very want & 15 & 34.09 \\
\hline Want & 29 & 65.91 \\
\hline Normal & 0 & 0 \\
\hline Do not want & 0 & 0 \\
\hline Very unwilling & 0 & 0 \\
\hline
\end{tabular}

$65.91 \%$ of students wanted and $34.09 \%$ very wanted to continue with similar learning activities for a number of reasons: "I can acquire new and new knowledge", "Like teaching methods", "I want to know more ways to solve mathematical problems", "Time is mostly for students", "Fun, exciting, absorb good lessons", "I want to practice my mathematical skills and from the above activities, I will be able to entertain after tired classes", "Good, rewarding, applicable to many other subjects such as student, chemistry ...", "Help the atmosphere more fun, easier for you to participate in activities", "I can learn better in mathematics", "Very happy, more exchange with friends", ... A large number of students' responses showed that they had a positive belief in this teaching method and wished to continue learning with such activities.

\section{Conclusions}

The students were introduced four methods of solving quadratic equations, in which two from mathematical history associated with two mathematicians, Viète and Descartes. The researchers conducted teaching through the worksheets with integrated solution methods. By evaluating the teaching process, the results showed that students were quite excited about the methods and that they were more receptive to the lesson. In addition, while teaching students also participated in group discussion activities, from the knowledge that students discussed was more fun, students always actively sought out knowledge, not restrictive, impose, comfortable classroom atmosphere. The study reinforced the other existing results $[8,15,17]$.

The mathematical knowledge could not be strange to students, but the history of the problem was completely new. Also, the approach of mathematical history was for reference only, not too heavy, not compulsory, without inference as learning mathematical knowledge, creating conditions for students to easily access. Through the process of implementing learning activities, students were active, proactive, excited and happy to acquire knowledge. In addition, it was the extra-curricular study sessions and group discussion activities that helped students confidently and boldly expressed their opinions, knowledge not only learned from teachers but also from friends. From there, the group activities created the closeness and solidarity between students, as well as the friendliness between teachers and students.

Students in the experimental class knew the knowledge of mathematical history related to the problem, they mastered the different methods, the origin of knowledge and some related mathematicians. This result was similar to the researches $[7,15]$. Through the experimental process with the achieved results, some conclusions were drawn. The learning process created for students more excited in learning, more lively classroom. In addition to simple knowledge of knowledge, it provided students with useful information, interesting stories and mathematicians associated with knowledge. These similar comments were also given in the literature $[7,15,20]$. Therefore, it is fully suitable to incorportate mathematical history into teaching.

One implication was that students encountered some difficulties regarding the two methods of Viète and Descartes; from here, the teacher also needs to encourage students to see that such difficulties have also occurred to mathematicians in history, so they don't need to be so worried. Another implication can be deduced that problems that pertain to mathematicians' inventions can be included in the curriculum for students to solve. This also shows respect for mathematical history and preserves the scientific features of mathematical knowledge because currently the mathematical knowledge is presented in a way that is consistent with the general perception of the mathematical community; nevertheless it sometimes leads to deviations from the history of knowledge.

The potential of integrating mathematical history into teaching has been clarified in the literature, so in the context of Vietnam, teachers can organize extracurricular activities on mathematical history. Also, they can also flexibly introduce biographies as well as anecdotes of mathematicians associated with the knowledge of the mathematics they are about to teach in order to motivate students to learn, thereby making the learning atmosphere more comfortable. In order to be more effective, teachers need to be knowledgeable about the history of mathematics and even more importantly, they need to master the methods of integrating math history in the classroom. The fact is also found that the mathematical history is not integrated into the test as well as the assessment process of student learning. A proposal is made that teachers can give students encouragement scores when they participate in math learning activities that incorporate historical elements.

\section{REFERENCES}

[1] C. Bellomo, C. Wertheimer. A Discussion and Experiment 
on Incorporating History into the Mathematics Classroom, Journal of College Teaching \& Learning, Vol.7, No.4, 19-24, 2010.

[2] S. O. Butuner. Using History of Mathematics to Teach Volume Formula of Frustum Pyramids: Dissection Method, Univeral Journal of Educationa Research, Vol.3, No.12, 1034-1048, 2015.

[3] M. Dejić, A. M. Mihajlović. History of Mathematics and Teaching Mathematics, Univeral Teaching Innovations, Vol.27, No.3, 15-30, 2014.

[4] M. N. Fried. Can Mathematics Education and History of Mathematics Coexist?, Science \& Education, Kluwer Academic Publishers, 391-408, 2001.

[5] J. M. Furner, E. A. Brewer. Associating Mathematics to Its History: Connecting the Mathematics We Teach to Its Past, Transformation, Vol.2, No.2, Article 2, 2016.

[6] D. Galante. The Use of the History of Mathematics in the Teaching Pre-service Mathematics Teachers, Journal of Reseach in Mathematics Education, Vol.3, No.2, 110-120, 2014.

[7] S. Goktepe, A. K. Ozdemir. An Example of Using History of Mathematics in Classes, European Journal of Science and Mathematics Education, Vol.1, No.3, 125-136, 2013.

[8] N. Haverhals, M. Roscoe. The History of Mathematics as a Pedagogical Tool: Teaching the Integral of the Secant via Mercator's Projection, The Mathematics Enthusiast, Vol.7, No.2, Article 12, 2010.

[9] L. B. Horton, R. M. Panasuk. Raising Awareness the History of Mathematics in High School Curriculum, International Journal of Humanities and Social Science, Vol.1, No.16, 2011.

[10] U. T. Jankvist. A Categorization of the "Whys" and "Hows" of Using History in Mathematics Education, Educational Studies in Mathematics, No.71, 235-261, 2009.

[11] G. B. Karaduman. A Sample Study for Classroom Teachers Addressing the Importance of Utilizing History of Math in Math Education, Procedia Social and Behavioral Sciences, Vol.2, 2689-2693, 2010.

[12] J. M. Mendoza, J. M. T. Alegario, M.l G. Blanco, R. de Torres, R. B. Igay, L. E. Elipane. Integrating History of Mathematics in Teaching Cartesian Coordinate Plane: A Lesson Study, Korean Society of Mathematical Education, Vol.20, No.1, 39-49, 2016.

[13] R. M. Panasuk, L. B. Horton. Integrating History of Mathematics into the Classroom: Was Aristotle Wrong?, Journal of Curriculum and Teaching, Vol.2, No.2, 37-46, 2013.

[14] R. M. Panasuk, L. B. Horton. Integrating History of Mathematics into Curriculum: What are the Chances and Constraints?, International Electronic Journal of Mathematics Education, Vol.7, No.1, 7-20, 2013.

[15] P. Liu. Do Teachers Need to Incorporate the History of Mathematics in Their Teaching? Mathematics Teacher, Vol.96, No.6, 416-421, 2003.

[16] B. Smestad, U. T. Jankvist, \& K. Clark. Teachers' Mathematical Knowledge for Teaching in Relation to the
Inclusion of History of Mathematics in Teaching. Nordic Studies in Mathematics Education, Vol.19, No.3-4, 169183, 2014.

[17] U. T. Jankvist. Teaching History in Mathematics Education to Future Mathematics Teacher Educators. CERME 9 Ninth Congress of the European Society for Research in Mathematics Education, Charles University in Prague, Faculty of Education; ERME, Prague, Czech Republic, 1825-1831, 2015.

[18] S. Sen. Integrating History of Mathematics into the Mathematics Teaching: a Study on Concept of Variable in Elementary Algebra in Indian Perspective, International Journal of Multidisciplinary Education and Research, Vol.2, No.1, 16-19, 2017.

[19] T. D. Vittori. Analyzing the Use of History in Mathematics Education: Issues and Challenges around Balacheff's cKff Model. Educational Studies in Mathematics, Springer Verlag, Vol.99, No.2, 125-136, 2018.

[20] C. YÕldÕz, B. Ö. Çabakçor, Z. B. Özdo $\div$ an, S. Arslan. The Views of the Teacher and Students in Regards to the Use of the History of Mathematics in the Teaching of Fractal Subject, Procedia Social and Behavioral Sciences, Vol.15, 868-872, 2011. 